\title{
A Comparative Study of patients, Undergoing Transurethral Resection of Prostate Gland With Or Without Otis Urethrotomy Before Surgery - A Single Institution Experience
}

\author{
Shrestha NM
}

\begin{abstract}
Background: Transurethral resection of prostate (TURP) is considered as the gold standard surgical treatment for Benign prostatic Hyperplasia (BPH). Among many post TURP complications, urethral stricture is one of the most dreaded urological complication, which may result in life long misery. The present study aimed to report the outcomes of Otis urethrotomy to prevent urethral stricture before TURP. Method: This was a comparative study between two equal groups of 100 patients who met inclusion criteria. Study conducted in the department of surgery, Urology unit, Nepalgunj Medical College from 2014 May to 2016 April. In group A, included all the patients underwent TURP without Otis urethrotomy and in group $B$, included all patients underwent TURP after doing Otis Urethrotomy. The patients were evaluated for evidence of urethral stricture formation. Result: In Group A, 20 patients out of $100(20 \%)$ developed urethral stricture whereas in Group B, 8 patients out of $100(8 \%)$ developed urethral stricture .The rate of Urethral Stricture in Group A is significantly more than in Group B $(p<0.05)$. Conclusion: The incidence of urethral stricture formation can be significantly reduced by doing Otis urethrotomy before TURP than TURP alone.
\end{abstract}

Key words- TURP, otis urethrotome, urethrotomy, stricture

\section{INTRODUCTION}

TURP is considered as the gold standard surgical treatment for $\mathrm{BPH}$ throughout the world. In the 1986 National Health Survey, $96 \%$ of the patients undergoing prostate surgery for $\mathrm{BPH}$ had TURP. It was estimated that 350,000 Medicare patients had a TURP that year ${ }^{1}$. First TURP was reported in 1932. In 1876, the American Fessenden N. Otis developed a dilating urethrotome with a calibrating device.

An Otis urethrotomy is the blind transurethral incision of the urethra by an Otis urethrotome. After insertion of the Otis urethrotome, the urethra is dilated to the desired width and a blade cuts the stretched urethra at the 12 o'clock position. The Otis urethrotomy is reserved for the palliative treatment of long-segment strictures of the male urethra or to treat proximal narrowing of the female urethra. Otis urethrotomy is also performed before the use of resectoscopes $(>26 \mathrm{CH})$ in a narrow urethra to prevent ischemic damage ${ }^{2}$.

Like other surgeries, it is also not free from complications, such as TURP syndrome, urinary incontinence, bladder perforation, haematuria, septicemia. Urethral stricture is one of the late complication following TURP ${ }^{3}$. The urethra receives considerable trauma from instrumentation during TURP. In

Dr. Naresh Man Shrestha

Address for correspondence:

Dr. Naresh Man Shrestha

Department of Urology

Nepalgunj Medical College Teaching Hospital,

Kohalpur, Banke, Nepal

Email: drnms1973@gmail.com most cases, the urethra heals without sequels. However, in $<10 \%$ of patients the urethra heals by forming scar tissue that causes blockage of the lumen. This complication is treated with dilation or transurethral incision to re-establish urethral patency ${ }^{4}$.

This study compares the incidence of urethral stricture formation in patients undergoing TURP with or without using Otis urethrotomy before surgery.

\section{MATERIALAND METHODS}

It is comparative study conducted from May 2014 to April 2016 in the department of surgery, urology unit, in NGMC. The patients, who met inclusion criteria, were divided into two group. Group A consisted the patients who underwent TURP alone and group B consisted those who underwent Otis urethrotomy before TURP.

Inclusion criteria for the present study were as follows:

I. Patients who have no previous history of catheterization, urethral manipulation or trauma.

II. Patients who did follow up.

III. Patients who have no previous history of urethritis.

IV. Patients with no history of urethral stricture, meatal stenosis or passage of stone from urethra.

V. Patients with no additional procedure during TURP like per urethral cystolithotripsy or litholapaxy.

All patients were examined with Ultrasonography, $x$-ray, kidney ureter bladder (KUB), urine for routine, culture and sensitivity, prostate specific antigen. In some performed cystoscopy also. Further the patients were studied for clinical history and clinical examination. Routine laboratory test for operation were done. 
lubricated (with xylocain gelly) Otis urethrotme was introduced inside the urethra with the knife hidden inside the instrument. Instrument inserted up to bulbar part of urethra. After opening the instrument to $25-28 \mathrm{fr}$, the cut was made by moving the roof like knife from the resting position and pulling it back at the 12 o clock position before TURP done. $26 \mathrm{fr}$ karl storz TURP sheath with resectoscope and $1.5 \%$ glycine used as a continuous irrigating fluid to cut prostate. At the end of procedure $24 \mathrm{fr} 3$ ways foley's catheter placed with $50 \mathrm{ml}$. distil water inflated balloon which was kept on traction for 24 hours. Catheter removed after 48 hours, patient discharged on third or fourth post operative day.

All patients were followed up. Patients who complained of lower urinary tract syndrome (LUTS) underwent Ultrasonography (USG), urine test, cystoscopy to confirm urethral stricture formation. All the patients in follow up who diagnosed with urethral stricture were treated with filliform follower urethral dilation and further self calibration.

\section{Statistical analysis:}

Data analysis was performed with the program statistical package for social science (SPSS version 17.0). The qualitative variables were presented as frequency and percentage. For the parametric test of two independent group data, independent ttest was used. A $p$-value less than 0.05 was considered statistically significant ${ }^{5}$.

\section{RESULT}

Total number of patients were 200, one hundred in each group. The age ranged from $62-79$. The types and the respective rate of findings in both groups of patient having complain with lower urinary tract syndrome (LUTS) were detected through Ultrasonography (USG), urine test, cystoscopy are shown in the Table -I Furthermore, the common site of ureteral stricture is shown in the Table-II.

\section{DISCUSSION}

Enlargement of prostate gland is one of the main cause of bladder outlet obstruction in old age male patient. Due to associating other disease like chest infection and heart disease in this group, operating is so challenging.Since the TURP has developed, the complication has redused in comparision to open surgery. But still it has also complications . urethral stricture formation is one of the late comlication in any prostate surgery but TURP has reduced the incidence but still ranges between $7-9 \%^{6,7}$. But the routine use of internal Otis urethrotomy before TURP reduces the chance of urethral stricture formation ${ }^{8,9}$

This study also showed the advantages of Otis urethrotomy before TURP.By using Otis urethrotome decreases the rate of urethral stricture is due to increment of urethral caliber and decreases the chance of urethral injury caused by stretching and friction from wide resectoscope sheath. Although trauma during surgery is the commonest cause, but post operative urethritis caused by indwelling catheter or infection can also result in stricture formation. This is particularly true if the catheter is of large size and keeps for longer time. In addition the incidence of stricture formation is related to the size of gland and duration of resection ${ }^{10}$.

The present study showed the commonest site of urethral stricture formation was at meatus and this finding is supported by the study of Bilal $\mathrm{H}$ and Walton JK et. studies ${ }^{11,12}$.

\section{CONCLUSION}

This study revealed that performing Otis urethrotomy before TURP can reduce the incidence of urethral stricture formation significantly than TURP alone.

\begin{tabular}{|l|c|c|c|}
\hline Findings & $\begin{array}{c}\text { Group A (only TURP) } \\
\text { n (percentage ) }\end{array}$ & $\begin{array}{c}\text { Group B (TURP + Otis urethrotomy ) } \\
\text { n (percentage ) }\end{array}$ & P-value \\
\hline Urethral stricture formation & $20(20 \%)$ & $8(8 \%)$ & $<0.05$ \\
\hline UTI & $11(11 \%)$ & $9(9 \%)$ & $>0.05$ \\
\hline Mild BPH & $15(15 \%)$ & $16(16 \%)$ & $>0.05$ \\
\hline
\end{tabular}

$\mathrm{n}=$ number of patients with respective findings.

Table I : Incidences of urethral stricture formation and others.

\begin{tabular}{|c|c|c|}
\hline Part of urethral stricture & Number of patients & Percentage (\%) \\
\hline Penile urethra & 8 out of 28 & $28.57 \%$ \\
\hline Meatus & 20 Out of 28 & $71.42 \%$ \\
\hline
\end{tabular}

Table II: common site of urethral stricture $(n=28)$ 


\section{REFERENCES}

1. Lingeman JE, Matlaga BR, Evan AP. Campbell-Walsh Urology, 9th ed. Philadelphia: Elsevier; 2007.p 2829

2. Pansadoro und Emiliozzi 1998 PANSADORO, V. ; EMILIOZZI, P.:Die Urethrotomia interna. In: Urologe A 37 (1998), S. 21-24.

3. Nielsen KK, Nording J, Urethral stricture following transurethral prostatectomy.urology, 1990;35:18

4. Muta M. Issa, Fray F. Marshall,Contemporary Diagnosis and Management of Disease of the Prostate,3rd ed.pennsylvania:Handbooks in Health Care Co;2009.p110

5. Marusteri M , Bacarea V. Comparing groups for statistical differences: how to choose the right statistical test ?BiochemicalMedica.2010;20(1):15-32.

6. Lentz HC, Jr Mebust WK, Fort JD, and Melchior J. Urethral Stricture following TURP: Review of 2,223 resections. J Urol, 1997;117:194.

7. Jorgensen $\mathrm{PE}$, Weis N, Bruno E. Etiology of urethral Stricture following TURP. Scand J Urol Nephrol 1986;20:253.

8. Emmet JL, Roos SN, Greene LF, et al.Preliminary internal urethrotomy in 1036 cases to prevent urethral stricture following Tur: Caliber of normal adult urethra. J Urol $1964 ; 82: 51$.

9. Bailey Mj and Shearer RJ. The role of internal urethrotomy in the prevention of urethral stricture following TURP.Brit J Urol 1977;51:28.

10. Lundhus E, Dorfinger T, Moller-Madsen B, et al. Significance of the extent of TURP for post operative complications.Scand J urol nephrol 1987;2:9

11. Bilal H. Post prostatectomy Stricture. Clinical evaluation and management. J of post graduate medical institute, 1986;1:42.

12 Walton JK, Wright WL, Robinson PG and Nacey JN. The Meatal problem with TUR prostate: The value of post operative self dialation. Brit J Urol,1984;56:202. 